\title{
O ARBÍTRIO DO JUÍZO - ATUAÇÃO JUDICIAL CONTEMPORÂNEA: LIBERDADE OU ARBITRARIEDADE?
}

\author{
Ronaldo José de Sousa Paulino Filho*
}

\begin{abstract}
RESUMO
O artigo tem por objeto de estudo uma análise descritiva do papel do Poder Judiciário brasileiro na sociedade contemporânea e sua relação com o Estado Democrático, tratando dos dilemas relacionados a sua atuação, seu protagonismo e uma possível arbitrariedade. Para tal, utiliza de doutrina específica e uma pesquisa descritiva sobre a realidade atual. Trata-se de um debate fundamental e de grandiosa importância na atualidade, levando-se em conta que as consequências de um possível uso arbitrário da atuação judicial podem ser de complexidade negativa, ocasionando efeitos colaterais e riscos severos de entrave ao respeito do ideal democrático e para a sociedade. Busca ainda a análise se a discricionariedade pode se reverter em arbitrariedade entre outros aspectos relativos à temática como o decisionismo, livre convencimento. Com a finalidade de apresentar medidas e instrumentos para um melhor respeito do poder judiciário aos parâmetros da teoria constitucional., É necessário constante foco e comprometimento, analisando condutas e as decisões na busca de afastar a instabilidade e insegurança jurídica, que se estabelecem nos confrontos entre ativismo e autocontenção da esfera política com finalidade na luta pela democratização do Poder Judiciário brasileiro e no sentido da efetivação de direitos, discutindo os desafios da democracia com a intenção de defesa da Constituição.
\end{abstract}

PALAVRAS-CHAVE: Poder Judiciário. Estado Democrático de Direito. Atuação. Protagonismo Judiciário. Direitos Fundamentais. Justiça.

\begin{abstract}
The papper aims to study a descriptive analysis of the role of the Brazilian Judiciary in contemporary society and its relationship with the Democratic State, dealing with the dilemmas related to its performance, its protagonism and a possible arbitrariness. For this, it
\end{abstract}

* Mestre em Direito, Especialista em Direito Constitucional Aplicado, Direito Processual Civil, Advogado, Professor e Pesquisador. 
uses specific doctrine and a descriptive research on the current reality. This is a fundamental debate of great importance today, bearing in mind that the consequences of a possible arbitrary use of judicial action can be of a negative complexity, causing side effects and severe risks of hindering respect for the democratic ideal and for the society. It also seeks to analyze whether discretion can be reversed in arbitrariness among other aspects related to the issue such as decisionism, free convincing. With the purpose of presenting measures and instruments for a better respect of the judiciary to the parameters of the constitutional theory., It is necessary constant focus and commitment, analyzing conducts and decisions in the quest to remove the instability and legal insecurity that are established in the confrontations between activism and self-restraint of the political sphere with a purpose in the struggle for the democratization of the Brazilian Judiciary and in the sense of the realization of rights, discussing the challenges of democracy with the intention of defending the Constitution.

KEYWORDS: Judiciary. Democratic State. Acting. Judicial Protagonism. Fundamental Rights. Justice.

\section{INTRODUÇÃO}

O estudo parte de duas formulações principais que demonstram a complexidade e importância do tema na sociedade contemporânea, que são: De que forma a politização errônea e indevida da justiça e o transbordar dos limites da capacidade institucional do Poder Judiciário resultam no uso arbitrário da jurisdição desrespeitando os direitos fundamentais através da flexibilização de direitos e garantias individuais? Como o chamado ativismo judicial e sua relação com o Estado Democrático pode ser equilibrada com base no papel de protagonismo atual desempenhado pelo judiciário e quais limites de sua atuação?

Analisar descritivamente a atuação do Poder Judiciário contemporâneo para apresentar mecanismos e instrumentos que possam equilibrar as relações institucionais e o Estado Democrático de Direito, no sentido de coibir possíveis condutas arbitrárias que o protagonismo judicial estabelece na sociedade, como o desrespeito aos direitos fundamentais, consiste em tarefa da maior importância para a doutrina constitucional atual, levando-se em conta todas mudanças e 
reiteradas situações atuais envolvendo o judiciário. Buscar e alertar a compreensão dos acontecimentos e possíveis críticas ao modelo de prestação da jurisdição é o objetivo de tal estudo com a finalidade de melhor aplicação da Justiça e a Democracia.

Fenômeno da realidade político-social brasileira, acompanhado de um forte crescimento é o possível desempenho ativista do Poder Judiciário, nos mais variados debates, desde o cidadão leigo até a mais respeitada doutrina, esse protagonismo exercido por aquele é amplamente discutido e polemizado. Essa postura alcança desdobramentos dos mais diversos níveis, e engloba variados preceitos desde a estrutura dos poderes; harmonia institucional; postura antiformalista; desempenho das instituições e principalmente alcança uma extrema repercussão social.

\section{DILEMAS ENTRE ATUAÇÃO, PROTAGONISMO, ARBITRARIEDADE}

Frequente são as notícias, os comentários e discussões envolvendo a postura do poder judiciário atual, nos mais diversos meios de comunicação e sociais, muitas delas levam a questionamentos e alarme por parte do meio acadêmico-jurídico. Posições avessas ao ordenamento constitucional vigente e os mais variados excessos cometidos por quem exerce a jurisdição.

Sobressalta diversas posturas e atitudes recentes que causam no mínimo questionamentos sobre sua legalidade como: indício e presunções viram prova, prova é transformada em uma convicção e juiz condena réu baseado em meros relatos de delatores; frases do tipo "em tempos excepcionais, medidas excepcionais", são chanceladas ; ex-ministro de Tribunal Superior diz que foi conivente com vazamento, sob o argumento de que a ilegalidade era para o bem; ocorre a institucionalização da ausência de prazo para prisões preventivas; decisões que decretam prisões baseadas em argumentos morais e políticos; condenações sem alicerces probatórios; juiz que censura alegando mau gosto estético; e por fim as frequentes espetacularizações das prisões. Entre tantos outros fatos que vem se tornando rotina na realidade atual.

Neste cenário ainda se verifica muitos posicionamentos com o víeis político das decisões por parte do Supremo Tribunal Federal e 
uma interferência nas atribuições dos Poderes que alicerçam o Estado Democrático. É relevante uma preocupação de que o judiciário e suas decisões se apresentem como mecanismos de desconstrução do direito, com finalidade eminentemente política. A diminuição da importância da imparcialidade do juiz termina se configurando natural por boa parte da sociedade e do meio jurídico, possibilitando assim a figura de "juízes heróis" ou mesmo juízes "semideuses" que se ligam e se submetem às chamadas maiorias de ocasião ou de uma parcela da sociedade.

Diante de tantos fatos frequentes na realidade atual, uma lei referente ao abuso de poder chegou a ser duramente criticada por parte da comunidade jurídica, através de associações de magistrados, procuradores, entre outros. O discurso de excepcionalidade vai de encontro ao pensamento racional que os fins não justificam os meios. Os meios democráticos são caracterizados por demarcações que existem para evitar o arbítrio e a opressão, além de contrapor a lógica de normas internacionais de proteção a pessoa humana, e a violação frontal ao Estado Democrático de Direito.

O primeiro grande objeto do constitucionalismo moderno é a democracia; o segundo é sua limitação, (ACKERMAN, 2011, p. 996). Neste sentido é o que se baseia o presente estudo, na análise do papel exercido pelo judiciário atual e sua relação com o Estado Democrático, partindo para investigação de premissas relativas aos dilemas entre a atuação e como esta se estabelece, protagonismo e um possível uso arbitrário, que se constatadas oferecem um risco não só ao equilíbrio institucional, mas aos direitos e garantias individuais.

No Estado de Direito não é admissível e inaceitável flexibilizar direitos e garantias individuais em nome do duelo deste ou daquele delito. A investigação, a acusação e o julgamento devem ser dirigidos pelos princípios do devido processo legal, da presunção de inocência, do contraditório, da ampla defesa, da proibição de prova ilícita, do juiz imparcial, da proporcionalidade entre outros.

Termos como o "Lawfare", significando que as instituições jurídicas são abusivamente utilizadas para a perseguição de um adversário político. Sendo uma arma destinada a destruir o inimigo, mal utilizando, e abusando do sistema legal e da mídia, com finalidade de conseguir o clamor público. "Juristocracia" que deriva da obra "Towards Juristocracy", mencionando que as elites políticas, 
econômicas e sociais transferem poder ao Judiciário, quando ameaçadas de perder a hegemonia na esfera política, e Judicialização hoje são discutidos como reflexos de uma atuação do poder judiciário atual e muito questionadas com base em um possível excesso aos limites da jurisdição. O cenário político, econômico e social em que se encontra o Brasil e que se aproxima com a realidade de alguns países vizinhos da América Latina termina favorecendo fenômenos de desequilíbrio institucional e interferência de um poder sobre o outro.

Tal análise crítica é imperativa, uma vez que, no Estado Democrático de Direito, o que se espera não é apenas o resultado, mas que seja obtido a partir de meios legítimos. Os princípios em questão são frutos de intensas aquisições da humanidade. Nos períodos da história em que se abriu mão do respeito desses direitos, as consequências não foram boas para a sociedade.

Dentro de uma lógica contemporânea de estabelecer o Direito é natural um desenvolvimento e alteração do formalismo passado, até mesmo pela ampliação da ordem constitucional pós 1988. No entanto até onde essas alterações de atuação resultam, as razões e consequências de um protagonismo judicial e seus limites devem ser bem estruturados e estudados por parte da Teoria Constitucional.

$\mathrm{O}$ respeito e conformidade com critérios interpretativos firmes também são questionados na atualidade sendo alvo de variados estudos da doutrina constitucional e fornecem parâmetros de limitação, por exemplo, conforme menciona Konrad Hesse, o limite da textualidade "é pressuposto da função racionalizadora, estabilizadora e limitadora do poder da Constituição" (HESSE, 1998, p. 69-70). Se o intérprete não respeita os parâmetros constitucionais, ele não mais interpreta, mas sim modifica ou gera um rompimento com a Constituição.

O Judiciário se configura como o último pilar da busca pela justiça, não podendo se submeter ao ritmo instável e mutável da opinião pública, dessa forma ao se escutar falar que "determinado juiz me representa", frase banal em períodos de espetacularização na performance judicial e politização do Judiciário, demonstra o desrespeito à noção de separação de poderes ou uma possível instabilidade constitucional.

Dessa forma, os técnicos não podem definir de forma unilateral e impositiva que grau de risco a sociedade deseja correr em 
função do suposto avanço, conforme abordagem pelo sociólogo alemão do "Risikogesellshaft" (BECK, 2011). Os direitos e garantias fundamentais, que na concepção de Luigi Ferrajoli, compõem o conteúdo substancial da democracia precisam sempre serem respeitados. Um desrespeito institucional por parte do Poder Judiciário através de condutas ativistas vem sendo amplamente debatido e polemizado como menciona (STRECK, 2014, p. 47).

\begin{abstract}
"As recentes decisões ativistas da Corte Constitucional do Brasil falam mais sobre a democracia exercida em terrae brasilis do que sobre a própria atuação do Supremo Tribunal Federal. Ora, as aberrações hermenêuticas vistas são frutos do casamento entre uma tripartição falida dos Poderes e um oportunismo judicial. São tempos de revisão de conceitos a fim de que não se radique nesta Terra de Vera Cruz um velho terror com novas feições: o Leviatã (agora) judicial. "
\end{abstract}

Na tentativa de empreender um estudo que possibilite a análise de prováveis respostas ao problema e da urgência de uma teoria judicial que esteja adequada a fornecer respostas corretas no vigente Estado Democrático de Direito, como forma de recorte do tema, a pesquisa visa a entender as perspectivas sobre a função jurisdicional da magistratura na sociedade atual.

Uma nova estrutura do constitucionalismo favorece um possível ativismo e não obstante os países adeptos do "common law”, favorecidos pela estrutura pautada pelo aspecto jurisprudencial, os países configurados como de "civil law" também ao se basearem em princípios e suas constituições com uma ampliada carga de valores, terminam por permitirem essa ampliação por parte da jurisdição constitucional. No entanto é preciso averiguar pelos padrões dogmáticos se tal atuação antes mencionada se configura como um protagonismo judicial, ativismo e se arbitrário, como menciona LIMA, 2014, p. 280).

"A identificação das situações e frequência com que a corte anula ou mantém os atos dos demais poderes e entes, determina a tomada de providências inseridas dentre as atribuições destes e outros, é importante para pôr em perspectiva a sua efetiva intervenção no sistema e, eventualmente, evitar ilações em torno de uma "ditadura judicial" ou intervenção "desmedida", desapegada de dados mais concretos." 
Sendo assim, é preciso com o cuidado em primeiro analisar atuação e papel desempenhado pelo Poder Judiciário, na busca de mecanismos para o exercício de uma jurisdição mais eficaz e equilíbrio institucional, o fato de não existir um órgão que possa corrigir as decisões equivocadas da nossa corte constitucional demonstra a necessidade de um controle externo da jurisdição, por exemplo. A fim de buscar um equilíbrio entre o Judiciário, a Democracia e a Justiça.

Vale a comunidade jurídica e mesmo a sociedade entender cinco pontos sobre a questão. O Primeiro ponto, consiste em analisar condutas contemporâneas do poder judiciário brasileiro de grande repercussão social, o estado democrático contemporâneo e sua relação com o judiciário, elencando interferências externas ao direito que propiciam tal possível atitude. É preciso pesquisa sobre determinadas condutas públicas de juízes, associações de magistrados e de tribunais específicos e analisando estudos referentes a gradações entre estado democrático e autoritário para enquadrar condutas do judiciário nas delimitações apresentadas.

Segundo marco consiste em um aprofundamento sobre teoria constitucional e teoria da decisão jurídica, seus modelos e delimitações, analisando se a discricionariedade pode se reverter em arbitrariedade entre outros aspectos relativos à temática como o decisionismo, livre convencimento, voluntarismo excessivo e técnica. O Terceiro foco consiste em estabelecer os parâmetros referentes ao ativismo judicial no estudo de uma descrição dogmática.

Quarto ponto se configura para estabelecer uma comparação com a realidade da América Latina e buscar uma aproximação com os países vizinhos analisando como se demonstra essa atuação e se desrespeita direitos e garantias fundamentais. O Quinto fator consiste na busca de medidas e instrumentos para um melhor respeito do poder judiciário aos parâmetros da teoria constitucional, averiguando se medidas como um maior controle do judiciário; medidas de combate ao abuso de poder; um diálogo e respeito com a corte interamericana de direitos humanos; respeito ao ordenamento internacional entre outras que freiem o possível desrespeito aos direitos fundamentais reflexos do protagonismo judiciário na atual conjuntura do País. 
Democracias contemporâneas podem enfrentar várias ocasiões de instabilidade e crises que convivem com instituições constitucionais, nesse cenário grupos minoritários ficam ainda mais vulneráveis. Sendo assim é preciso um criterioso estudo acerca dos limites do Poder na busca de afastar a instabilidade e insegurança jurídica, que se estabelecem entre ativismo e autocontenção da esfera política com finalidade na luta pela democratização do Poder Judiciário brasileiro e no sentido da efetivação de direitos, precisando assim discutir os desafios da democracia sempre com a intenção de defesa da Constituição.

Trata-se de um debate fundamental e de grandiosa importância para o desenrolar posterior do Estado Constitucional de Direito; a realidade social e a relação com a democracia. As consequências de um possível uso arbitrário da atuação judicial podem ser de demasiada complexidade negativa, ocasionando efeitos colaterais e riscos severos de entrave ao respeito do ideal democrático e para a sociedade.

É preciso entender o papel que os tribunais têm desempenhado na sociedade atual e em que medida as decisões judiciais podem funcionar como um (des)serviço da democracia. Com importância de uma análise descritiva do poder judiciário contemporâneo brasileiro que está inserido em um contexto de extrema complexidade e, portanto, opera em constante situação de risco. O risco para a legitimidade democrática, bem como de vetar ou ampliar direitos ou deveres da sociedade, aplicando e deixando de aplicar a Constituição, com o viés e legitimidade de "interpretar" a Lei a favor da política e não da justiça é o tipo de atitude que precisa ser estudada e debatida, demonstrando a relevância e importância temática para toda a comunidade jurídica.

Pelas avaliações dos textos e pela realidade observada, o ativismo judicial demonstra-se um tema de considerável preocupação para a sociedade brasileira, posto que, em não sendo usado com a devida cautela e excepcionalidade, possui todas as características de um poder "ditatorial" oculto, decidindo e executando questões que por muitas vezes não teria a competência e a capacidade necessárias para instituir um juízo. Logo, o ativismo demonstra-se passível de ser, claramente, uma forma de controle social e estatal, determinando e gerindo fatos e atos da vida social, bem como podendo ser utilizado 
como ferramenta de manobra nos bastidores políticos do País.

A precisa identificação dos limites a que se sujeita o Poder Judiciário no exercício da jurisdição, dada a natureza eminentemente jurídica dessa função estatal, assume contornos técnicos impossíveis de se afastar, por tal motivo demonstra a responsabilidade e importância da doutrina constitucional na busca de uma solução adequada ao problema posto.

\section{ASPECTOS DOUTRINÁRIOS-TEÓRICOS}

O afastamento do Poder Judiciário dos limites da sua competência para a aplicação de normas e uma postura autoritária ou arbitrária prejudica toda a ordem constitucional e principalmente a sociedade. A pretensão do estudo é o fortalecimento do Estado Democrático de Direito, sem o qual nenhum projeto político para o país se estabelecerá. A discursão do tema ora apresentado com centros acadêmicos e pesquisadores de outras realidades e com uma formação acadêmica social e cultural distintas, pode nos ajudar a fazer uma autocrítica da própria sociedade brasileira.

Vários autores tratam com a problemática em questão e fornecem uma construção de análises sobre o tema nos aspectos sociais e dogmáticos como exemplo: Lenio Streck, Glauco Salomão Leite, Mônia Henning Leal, Luiz Henrique Diniz Araújo, Flávia Santiago Lima, Humberto Ávilla, Gisele Cittadino, Luis Werneck Viana, Daniel Sarmento, Rafael Tomaz de Oliveira, João Maurício Adeodato, passando por um estudo da teoria da decisão jurídica e a hermenêutica com Dworkin, Kelsen entre outros que contribuem para estabelecer critérios de estudo e parâmetros de aplicação sobre o tema.

Dessa forma, tendo em vista que a observação da decisão judicial como construção social e sua relação com os demais sistemas sociais é objeto de estudo, (LUHMANN, 1990) descreve a relação entre sistemas sociais autônomos em uma sociedade moderna, colocando os tribunais e suas decisões como responsáveis por manter o primado funcional do sistema jurídico. É preciso então situar as configurações relativas ao poder judicial para comparar com o papel e realidade atual de atuação do Poder Judiciário.

Nesse sentido, é necessário tratar da questão da interpretação da norma e a decisão judicial fazendo uma distinção entre escolhas 
pessoais e pontos referentes aos princípios. O judiciário poderia intervir, no entanto não cabe manifestar preferências pessoais de seus membros ou de uma parcela social. Este entendimento é o proposto por (DWORKIN,1999). no direito como integridade, introduzindo uma racionalidade na decisão judicial, ao ponto, de forçar ao juiz uma resolução distinta àquela que seria seguida caso sua preferência valesse. O problema é a percepção que a realidade brasileira afasta a cientificidade do direito, coligada à lógica e se utiliza de decisionismos e voluntarismos que são sérios riscos ao Estado Democrático de Direito.

O primeiro e basilar dos parâmetros versa no requisito de que a interpretação constitucional seja ajustada com a intensidade de sentidos projetada pelo texto da norma. A interpretação e aplicação de natureza jurídica incide na edificação de normas reguladoras de conduta derivadas de textos prescritivos, vinculando a atuação do intérprete-aplicador, não é aceitável que a norma por este efetivada não encontre aderência à textualidade do dispositivo sobreposto.

Também é o entendimento de (CANOTILHO, 2003, p. 1208-9) que menciona "o texto normativo é, pois, ao mesmo tempo, o ponto de partida do processo hermenêutico e o mais expressivo balizador da adequação de seus resultados". Esse procedimento também é defendido por Lenio Streck no sentido das "bases para iluminação do compreendido" e a definição que Gadamer confere à interpretação, sendo o ato de especificar o compreendido como aponta (TOVAR, 2015, p. 532). Portanto, não satisfaz somente a explicação do fundamento legal da decisão, a justificativa deve ser protegida de uma subjetividade e tratar sobre todos os pontos mencionados pelas partes, não podendo assim estabelecer uma parcialidade. O Poder Judiciário deve corroborar o empenho com a fundamentação correta e nos parâmetros estabelecidos.

É referente à temática do ativismo e sua ligação com a interpretação que são posicionadas críticas e se retira um questionamento referente à discricionariedade, e seus limites. Uma diferenciação de discricionariedade como liberdade interpretativa e discricionariedade no comportamento, valendo-se da influência alemã concernente a discricionariedade de juízo e discricionariedade de atuação, o que na realidade brasileira se embaralham e quiçá seja o ponto central da postura ativista. A crítica diz respeito, a 
possibilidade discricionária do juiz, não em situar uma decisão com interpretação limitada ao dispositivo legal, a compreensão dos signos dos dispositivos legais, com aceitação explícita, mas em desenvolver uma disponibilidade sem limites de performance, não assim uma discricionariedade de juízo.

$\mathrm{Na}$ tentativa de suprir uma necessidade social pode fomentar abertura para um risco extremo de insegurança jurídica e social. (STRECK, 2009) faz ainda referência ao próprio Dworkin ao se referir a escolhas pessoais e livre convencimento por parte dos julgadores, com o uso de suas funções relacionando nesse caso a já discutida discricionariedade de juízo e de atuação, realçando o papel da legitimidade democrática, na resolução de conflitos de uma sociedade complexa:

"O risco que exsurge desse tipo de ação é que uma intervenção desta monta do Poder Judiciário no seio da sociedade produz graves efeitos colaterais. Quer dizer: há problemas que simplesmente não podem ser resolvidos pela via de uma ideia errônea de ativismo judicial. O Judiciário não pode substituir o legislador."

Nesse cenário de crise institucional se configura esse processo de transformação devendo ser confrontado o pensamento voltado ao estudo das relações entre direito, moral e política como os de John Rawls e Jürgen Habermas e as contribuições importantes de Chaïm Perelman, Ronald Dworkin e Friedich Müller entre tantos outros. Sempre com o intuito de proteger a jurisdição da prática de decisionismos, não pode, por exemplo, ser o livre convencimento refúgio de decisões arbitrárias.

O processo de alteração do estudo da teoria constitucional derivados do pós-positivismo e do neo constitucionalismo nos mostra a origem de determinadas condutas, no entanto, não se refere a uma evolução natural da forma de lidar com o Direito, mas o seu uso arbitrário ou ilegítimo que se encontra em estudo. (CAPELLETI, 1999 , p. 24) entende que a postura ativa dos magistrados seria perfeitamente natural ao mostrar que (...) "este fenômeno é inevitável, pois que toda interpretação tem uma porção intrínseca de criatividade. Nunca se confundindo com arbitrariedade, pois a criatividade respeita elementos processuais e substanciais"(...). Essa 
linha tênue de respeito e abuso podem ocasionar efeitos no fornecimento da prestação jurisdicional e sua relação com a sociedade como aponta (LOWENSTEIN,1976, p. 309): "quando os tribunais proclamam e exercem seu direito de controle, deixam de ser meros órgãos encarregados de executar a decisão política e se convertem por direito próprio num detentor de poder semelhante, quando não superior, aos outros detentores do poder instituídos”.

Dessa forma, a preocupação no que diz respeito à legitimidade e função do judiciário, é pautada em diversas críticas em relação atuação do judiciário, sua extrapolação de funções e o possível confronto com a soberania popular, muitos doutrinadores adotam posição semelhante, na contramão de atitudes que hoje na realidade brasileira parecem esquecidas, nessa linha segue (ÁVILA, 2009, p. 16):

"O Poder Judiciário não deve assumir, em qualquer matéria e em qualquer intensidade, a prevalência na determinação da solução entre conflitos morais porque, num Estado de Direito, vigente numa sociedade complexa e plural, deve haver regras gerais destinadas a estabilizar conflitos morais e reduzir a incerteza e a arbitrariedade decorrente da sua inexistência ou desconsideração, cabendo a sua edição ao Poder Legislativo e a sua aplicação, ao Poder Judiciário."

As origens desse processo de reformulação da teoria constitucional e da atuação judicial são trazidos, por variados aspectos que conjunturalmente podem explicar tais alterações, entendimento significativo é mencionado por (CITTADINO, 2002, p. 250):

"Várias são as chaves de interpretação desse processo que podem, inclusive, ser utilizadas para a análise da expansão do poder judicial tanto nos países centrais como nos periféricos: o fenômeno da normatização de direitos, especialmente em face de sua natureza difusa e coletiva; as transições pós-autoritárias e a edição de constituições democráticas, seja em países europeus ou latinoamericanos, com a consequente preocupação com o reforço das instituições de garantia do Estado de Direito, dentre elas a magistratura e o ministério público; as diversas investigações voltadas para a elucidação dos casos de corrupção a envolver a classe política, fenômeno já descrito como "criminalização da responsabilidade política"; as discussões sobre a instituição de algum tipo de poder judicial internacional ou transnacional, a exemplo do 
Tribunal Penal Internacional; e, finalmente, a emergência de discursos acadêmicos e doutrinários, vinculados à cultura jurídica, que percebem a expansão do poder judicial como reforço da lógica democrática."

O que em variadas notícias e posicionamentos de juízes e associações de magistrados atualmente pode se perceber é um talvez, processo de destruição do pensamento de 1988 (período pós autoritário), quem sabe explique uma crescente sensação de retorno a um autoritarismo por parte social, seja uma falta de efetiva justiça de transição que mostre a população os perigos e barbáries cometidos, onde o respeito aos direitos fundamentais sejam melhores empregados. Outra questão merece atenciosa preocupação, que seria a possibilidade nesse novo modelo de se estabelecer uma "juristocracia", onde os interesses de poucos, respaldados em uma maleabilidade hermenêutica, ensejariam em situações diferentes dos argumentos progressistas dos defensores do Neoconstitucionalismo. A realidade brasileira precisaria assim de mais rigor ou maleabilidade? Esse questionamento é difícil de ser respondido, mas interessante é a abordagem referente à Teoria Sistêmica de Niklas Luhman, por Marcelo Neves que é retirada de (SARMENTO, 2009, p. 26-27):

"Em sociedades periféricas, como o Brasil, não se desenvolveu plenamente este fechamento estrutural do Direito. Por aqui, fatores como a nossa "constitucionalização simbólica" geraram uma insuficiente diferenciação do Direito em relação a outros subsistemas sociais, permitindo que elementos a princípio estranhos ao código binário do jurídico - como a questão do poder político e do poder econômico (grifos nossos) - se infiltrem sistematicamente nos processos de aplicação das normas, condicionando o seu resultado. A teoria dos sistemas de Luhman não funcionaria bem entre nós, pois teríamos um Direito em boa parte alopoiético. Para tal perspectiva, esta maior abertura do Direito ao meio envolvente não assume o potencial emancipatório preconizado pela teoria neoconstitucionalista. Ela funciona muito mais como um mecanismo de cristalização de diferenças sociais, mantendo a hiper-inclusão de uns, ao preço da exclusão de outros."

Vale assim ressaltar a figura do judiciário na teoria de Luhmann, explicitando a busca da sociedade pelo judiciário para a 
possível produção de decisões políticas e a extrapolação do papel que o intérprete exerce atualmente na sociedade, que confirma a preocupação da pesquisa, conforme (EISENBERG,2002, p. 47):

"Falar, portanto, de uma judicialização da política significa dizer que o Judiciário está explorando conflitos no sentido de formar e reproduzir decisões vinculantes. Em vez de explorá-los para produzir expectativas comportamentais generalizadas (sua função sistêmica por vocação), o direito é invadido pela política, e seus agentes são crescentemente buscados pelos atores sociais para produzir decisões políticas."

É preciso sempre ressaltar que o direito é um meio de mudança social, longe aqui a intenção de esquecer ou retirar determinado preceito, a validade desse instrumento até mesmo de determinados institutos que bem colocados se inserem e interligam com o judiciário para efetivar direitos, ou mesmo mecanismos de maior participação social, são formas de uma melhora na prestação jurisdicional, mas ao constatar a realidade social brasileira percebese determinados possíveis excessos ou alterações dessa lógica, como apontado (STAMFORD DA SILVA, 2010, p. 143):

“Agora, se a questão é, porque no Brasil o direito é mais dependente da economia e da política que em outro países, uma resposta é porque a sociedade brasileira ainda não diferencia direito de economia e política. (...) Numa frase: numa sociedade de corruptos, não se pode esperar um direito honesto. A superação do jeitinho, das alternativas que o brasileiro costuma utilizar para sobreviver não se resolve exclusivamente pelo direito."

Posicionamentos próximos são inúmeros dentre os autores pesquisados, a preocupação com realidades sistêmicas de realidades periféricas também são propostas por (NEVES, 2006) ao mencionar que nas sociedades da modernidade periférica, a exclusão social conduz a uma situação de "corrupção sistêmica", onde o Brasil, estaria no contexto como um exemplo de uma sociedade na qual se nota a tenacidade de privilégios e exclusões que obstruem a construção de uma esfera pública pautada pela generalização institucional da cidadania. $\mathrm{O}$ uso indiscriminado pelo clamor social 
de mecanismos que alterem a segurança da Constituição e relacionando ao ativismo judicial a problemática da postura atual do intérprete causam receio de uma ampliação arbitrária de função e a vulnerabilidade e insegurança que tal conduta propicia para a sociedade e mais especificamente para as minorias.

Sendo assim a preocupação em relação ao respeito aos direitos fundamentais e uma análise de possíveis abusos de poder ou mesmo de gradações entre o autoritarismo e a democracia conforme (NEUMANN, 1969) devem ser reforçadas com base na "Fórmula do Objeto" de origem Kantiana, onde diz que todo ser humano deve ser tratado sempre como fim em si mesmo e não como meio para se atingir determinados objetivos. Para tal o respeito aos direitos fundamentais deve ser estabelecido como diz (SARLET, 2005, p. 70), "Os direitos fundamentais (...) formado pelas decisões fundamentais, da ordem normativa, (...) se tornam necessárias certas vinculações de cunho material para fazer frente aos espectros da ditadura e do totalitarismo". Dessa forma, a constituição caracterizada como um dever ser (sollen) precisa ser devidamente respeitada como forma de objetivo do ideal democrático e respeito ao Direito e Justiça.

\section{CONCLUSÕES}

Diante de todos os fatos recorrentes e a preocupação da teoria constitucional contemporânea vale a recomendação de estudo e aprofundamento sobre a temática e é preciso tentar descrever o processo de transformação do direito que resultou na flexibilização do princípio da legalidade e no fortalecimento do Poder Judiciário; Introduzir e contextualizar os conceitos de teorias da decisão jurídica e sua relação com atuação do judiciário; Averiguar atuação do poder judiciário na realidade brasileira sob o aspecto do respeito a constituição; Destacar as repercussões institucionais do assunto sob exame.

Além de principalmente: Analisar se a atuação contemporânea do judiciário se configura como autoritária ou arbitrária; Verificar se o mencionado protagonismo corresponde com a realidade e em que áreas o possível autoritarismo é mais frequente, em questões penais e políticas, nos parece que abusos são mais frequentes; Apontar se a referida atuação confronta direitos fundamentais; Comparar a realidade brasileira atual com a América Latina no que diz respeito a 
uma possível conjuntura latino-americana da performance judiciária; Buscar soluções e mecanismos para a efetividade de respeito aos direitos fundamentais.

A intenção desse breve apontamento é a de repensar o modelo atual que se apresenta fatos recorrentes relacionados à atuação do judiciário brasileiro e qual papel deve representar. As condutas que demasiadas vezes se têm conhecimento de interferência na atuação legislativa e do executivo, além de severos desrespeitos aos direitos e garantias fundamentais preocupam e devem ser debatidas com mais frequência pela comunidade jurídica, acadêmica e pela sociedade, para tentar coibir possíveis excessos cometidos.

$\mathrm{O}$ arbítrio do juízo diz respeito ao tipo de papel que o judiciário desempenha, o termo remete a liberdade, uma livre escolha e autonomia, poder, faculdade de decidir, de escolher, de determinar, dependente apenas da vontade, ideia ou medida conveniente expediente, mas também corresponde em determinados casos ao cometimento de excessos e uma arbitrariedade muitas vezes estabelecidas por uma atuação que passa dos limites constitucionais atribuídos ao poder judiciário.

A temática fica longe de ser esgotada por este escrito, que serve como base de reflexão e apontamento para o desenvolvimento e aprofundamento sobre a questão. Uma possível contribuição é a preocupação com os cinco pontos mencionados anteriormente, dessa forma pode ser possível o enfrentamento da problemática e uma melhor compreensão da atuação do judiciário brasileiro, para o alcance de um melhor equilíbrio institucional e respeito não só ao ordenamento jurídico constitucional, mas principalmente ao direitos e garantias fundamentais estabelecidos pela Constituição da República.

\section{REFERÊNCIAS}

ÁVILA, Humberto. "Neoconstitucionalismo": Entre a "Ciência do Direito" e o "Direito da Ciência. Revista Eletrônica de Direito do Estado. Número 17, Salvador janeiro fevereiro e março.2009.Disponívelem:<http://www.revistas.unifacs.br/index.php/redu/a rticle/viewfile/679/50> Acesso em 20 de set. 2017.

AVRITZER, Leonardo. Impasses da democracia no Brasil. Rio de Janeiro: Civilização Brasileira, 2016. 
BECK, Ulrich. Sociedade de Risco. São Paulo: Ed. 34, 2011.

CANOTILHO, José Joaquim Gomes. Direito constitucional e teoria da Constituição. 7.ed. Coimbra: Almedina,2003.

CAPPELLETTI, Mauro. Juízes Legisladores?. Sérgio Antonio Fabris Editor. Porto Alegre, reimpressão 1999.

CASARA, Rubens R. R. Estado Pós-Democrático - Neo-Obscurantismo E Gestão Dos Indesejáveis. Rio de Janeiro: Civilização Brasileira, 2017

CITTADINO, Gisele. Judicialização da Política, Constitucionalismo Democrático e Separação dos Poderes. In: A democracia e os Três Poderes no Brasil. VIANNA, Luiz Werneck, organizador. Belo Horizonte: Editora UFMG, Rio de Janeiro: IUPERJ/ FAPERJ, 2002.

DE GIORGI, Raffaele. Direito, democracia e risco: vínculos com o futuro. Porto Alegre: Sergio Antônio Fabris Editor, 1998.

DWORKIN, Ronald. O império do direito. Trad. Jefferson Luiz Camargo. São Paulo: Martins Fontes, 1999.

EISENBERG, José. Pragmatismo, Direito Reflexivo e Judicialização da Política. In: A democracia e os Três Poderes no Brasil / Luiz Werneck Vianna, organizador. Belo Horizonte: Editora UFMG, Rio de Janeiro: IUPERJ/ FAPERJ, 2002.

GLOPPEN, Siri; GARGARELLA, Roberto; SAKAAR, Elin (Ed.). Democratization and the judiciary: the accountability functions of courts in new democracies. London: Frank Cass, 2004.

HESSE, Konrad. Elementos de Direito constitucional da República Federal da Alemanha. 20. Ed. Alemã. Trad. Luís Afonso Heck. Porto Alegre: Sérgio A. Fabris Editor, 1998.

HIRSCHL, Ran. Towards juristocracy: the origins and consequences of the new constitutionalism. Harvard University Press, 2004.

LAKATOS, Eva Maria; MARCONI, Marina de Andrade. Metodologia do trabalho científico. São Paulo: Atlas, 1995.

LIMA, Flávia Santiago. Jurisdição constitucional e política: ativismo e autocontenção no STF: Curitiba: Juruá, 2014.

LOWENSTEIN, Karl. Teoría de la constituición. Barcelona: Ariel, 1976.

LUHMANN, Niklas. A posição dos Tribunais no sistema jurídico. In: Revista da Ajuris. N. ${ }^{\circ}$ 49. Porto Alegre: Ajuris, julho de 1990.

NEUMANN, Franz: Estado Democrático e Estado Autoritário. Rio de Janeiro: Zahar, 1969 (trad. Luiz Corção). 
NERY JÚNIOR, Nelson. Anotações sobre mutação constitucional Alteração da Constituição sem modificação do texto, decisionismo e Verfassungsstaat". In: Direitos Fundamentais e Estado Constitucional. Ingo Wolfgang Sarlet e George Salomão Leite (org.) São Paulo: Revista dos Tribunais, 2009.

NEVES. Marcelo. (Não) solucionando problemas constitucionais: transconstitucionalismo além de colisões. Lua Nova, São Paulo, v. 93, p. 201-232, 2014.

NEVES, Marcelo. Entre Têmis e Leviatã: uma relação difícil. O estado democrático de direito a partir e além de Luhmann e Habermas. São Paulo: Martins Fontes, 2006.

OLIVEIRA, T. M.; ARAÚJO, M. L. C. Judicialização da política e ativismo judicial: conceitos e o quadro brasileiro. Direito e Justiça (URI), v. 16, p. 119-136, 2016.

PAULINO FILHO, R. J. S. Entre o Legislador e o Intérprete: O Binômio Método-Mérito na Análise da ADPF 132/ADI 4.277. 1. ed. Porto Alegre: Símplissimo, 2017.

RAMOS, Elival da Silva. Ativismo Judicial: parâmetros dogmáticos. São Paulo, Saraiva, 2010.

SANTOS, G. F. (Org.); STRECK, L. L. (Org.); ARAÚJO, M. L. C. (Org.). Direitos e Democracia no Novo Constitucionalismo Latino-Americano. 1. ed. Belo Horizonte: Arraes Editores, 2016.

SANTOS, G. F.; TEIXEIRA, J. P. F. A.; ARAÚJO, M. L. C. Diálogo entre Tribunais e proteção de direitos humanos: dificuldades e perspectivas. A\&C. Revista de Direito Administrativo \& Constitucional (Impresso), v. 66, p. 267-282, 2016.

SARLET, Ingo Wolfgang. Dignidade da pessoa humana e direitos fundamentais na constituição federal de 1988. 5. ed. Porto Alegre: Livraria do Advogado, 2005.

SARMENTO, Daniel. O neoconstitucionalismo no Brasil: riscos e possibilidades. In: LEITE,George Salomão; SARLET, Ingo Wolfgang (orgs.). Direitos fundamentais e Estado Constitucional. Estudos em homenagem a J. J. Gomes Canotilho. São Paulo: Revista dos Tribunais, 2009.

STAMFORD DA SILVA, Artur. Decisão jurídica e mudança social. Para uma sociologia da decisão jurídica. Confluências (Niterói), v. 11, p. 121-150, 2010. Disponível em: http://www.confluencias.uff.br/index.php/confluencias/article/view/177 
Acesso em:10 de set 2017.

STRECK, Lenio Luiz. Verdade e consenso. Constituição, Hermenêutica e Teorias Discursivas. Da possibilidade à necessidade de respostas corretas em direito. 2. ed. Rio de Janeiro: Lumen Juris, 2007.

. Lenio Luiz; BARRETTO, Vicente de Paulo et al. Ulisses e o canto das sereias. Sobre ativismos judiciais e os perigos da instauração de um terceiro turno da constituinte. Jus Navigandi, Teresina, ano 14, n. 2218, 28 jul. 2009. Disponível em: 〈http://jus.com.br/artigos/13229>. Acesso em: 20 de set.. 2017.

TOVAR, Leonardo Zehuri. Promessas da modernidade e ativismo judicial. Revista Brasileira de Políticas Públicas. v.5, n.2, 2015. Disponível em:

<https://www.publicacoesacademicas.uniceub.br/RBPP/article/view/3059>. Acesso em: 08/10/2017.

VIANNA, L. J. W. ; VIANNA, L. W. ; CARVALHO, Maria Alice Rezende de ; MELO, Manuel Palacios Cunha ; BURGOS, Marcelo Baumann . A Judicialização da Política e das Relações Sociais no Brasil. 1a.. ed. v. 01. Rio de Janeiro: Editora Revan, 1999.

VILLAS BÔAS FILHO, O. Uma abordagem sistêmica do direito no contexto da modernidade brasileira. 2006. Tese (Doutorado em Direito) Faculdade de Direito - Universidade de São Paulo, São Paulo.

ZAFFARONI, Eugenio Raúl. Poder Judiciário: crise, acertos e desacertos. Trad.: Juarez Tavares. São Paulo: Revista dos Tribunais, 1995.

WALDRON, Jeremy. "The Core of the Case Against Judicial review". Yale Law Journal, No. 115, 2006. 
